\title{
Reconstruction of Lower Jaw by Iliac Bone Graft, Ex- perimental Study on Rabbit and Role of Mesenchymal Stem Cells
}

\author{
Raja Kummoona $^{1 *}$, Ali Shather Zayed ${ }^{2}$
}

${ }^{1}$ FDSRCS, Eng.FICD of Maxillofacial Surgery, Iraqi Board for Medical Specializations, Medical City, Baghdad, Iraq ${ }^{2}$ FICMS, Maxillofacial Surgeons, Al Wasty Hospital for Reconstructive and Plastic Surgery, Baghdad, Iraq

*Corresponding author: Raja Kummoona, FDSRCS, Eng.FICD Emeritus Professor of Maxillofacial Surgery, Iraqi Board for Medical Specializations, Medical City, Baghdad, Iraq, E-mail: dr_raja_kummoona@yahoo.com

\begin{abstract}
:
In this research, twelve young male Rabbits age of 3 months are weighted $1.25 \mathrm{~kg}$, divided in two groups of 5 Rabbits and 2 Rabbits were used as control. They were subjected to surgical osteoctomy by excising bone $1.5 \mathrm{~cm}$ from the body of the mandible and bone graft of $2 \mathrm{~cm}$ harvested from the iliac crest. The graft was fixed by soft stainless steel wire of $0.25 \mathrm{~mm}$, post-operative systemic antibiotic of ceftriaxone of $20 \mathrm{mg} / \mathrm{kg}$ IM of body weight for six days prescribed, oxidized regenerated cellulose mesh was used to cover the graft of group B.

After 3 months the experiment was terminated, the result were 2 Rabbits passed, one Rabbit end with infection and one with slight injury to Sciatic nerve without effect on mastication. The dyed Rabbits and one with infection were excluded from this experiment.

The cytological changes of bone grafting showed formation of healthy granulation tissue with mesenchymal stem cells derived from bone marrow of bony segments of the mandible with platelets growth factor (PDGF) and from periosteum and covering muscles with large amount of fibroblasts with tiny blood vessels. Osteoblast was noticed more with chondrocyte and osteoid tissue with bone graft that covered by Surgical mesh (oxidized regenerated cellulose) soaked in blood and covered bone graft of group B to get faster healing in group B than in group A.

The aim of this research to understand the cytological changes that occurred in the graft and recipient area.
\end{abstract}

Keywords: Bone Graft; Mandible; Iliac Crest; Rabbit; Mysenchymal Stem Cell

\section{Introduction}

Bone grafting an interesting topic ${ }^{[1]}$, practiced by maxillofacial surgeons, plastic reconstructive surgeons and orthopedic surgeons for restoring continuity of bone after radical tumor surgery, road traffic accident with loss of bone segment and in cases of post traumatic missile war injuries. Bone grafting been used for reconstruction of congenital facial deformity and for reconstruction of the Temporomandibular Joint (TMJ) by Chondro-Ossous graft in disease of TMJ and hemi facial microsomia facial deformities ${ }^{[2]}$.

Bone grafting is a surgical procedure by using transplanted bone to repair and rebuild deformity or damage bones. Bone grafting is a choice for repairing bones and the donor area from the iliac crest or rib or tibia. Our skeleton consist of bone matrix, the cells in the matrix is responsible for repair and healing bone ${ }^{[3,4]}$.

Bone graft was used as filler and scaffold to facilitate bone formation and promote bone healing, these grafts are bioresorbable and have no antigen-antibody reaction and act as mineral reservoir which induces bone formation ${ }^{[5]}$.

The possibilities of failure of bone grafting occurred because of many factors such as first infection, second failure of proper technique, third non-rigid fixation with movement between graft and bone, fourth tension of tissue on the graft, fifth presence of scar and poor blood supply and sixth due to unexpected infection. History of chemotherapy or deep X-ray therapy leads to failure of grafting. Bone grafting is a highly technical procedure required surgeons with expertise, knowledge and skill.

Many techniques were advocated and described for reconstruction of discontinuity defect of the mandible after tumor surgery or traumatic injuries ${ }^{[6]}$. Bone grafting widely used and considered as second tissue transplanted after blood transfusion.

Received date: May 1, 2018

Accepted date: June 06, 2018

Publish date: June 14, 2018

Citation: Kummoona, R., et al. Reconstruction of Lower Jaw by Iliac Bone Graft, Experimental Study on Rabbit and Role of Mesenchymal Stem Cells (2018) J Stem Cell Regen Biol 4(1): 20- 24 .

Copy Rights: (C) 2018 Kummoona, R. This is an Open access article distributed under the terms of Creative Commons Attribution 4.0 International License. 
In situation with no major soft tissue loss or previous chemotherapy or radiotherapy a good functional and esthetic result can be obtained by using autogenous bone graft from the rib in children and iliac crest in adult ${ }^{[6]}$.

Reconstruction of the mandible in children ${ }^{[7,8]}$, may lead to many problems as operating in a small operating field requires many instrumentation and traction of tissue. It is quite difficult to operate long term treatment on a child and young patients with presence of other problems such as unpredictable growth of residual deformity of the mandible.

The advantage of bone graft of the mandible, to provide a definitive biological reconstruction for creation denture bearing to human. There are many factors affecting the choice of bone graft for reconstruction, these factors are type of the tumor benign or malignant, age of the patient, younger people responded more quickly and showed faster in healing time, good general condition of the patient, future follow-up and patient disease prognosis. These factors are vital points for success of bone grafting.

Bone elongation of the mandible can be achieved by distraction technique ${ }^{[9]}$. Distraction defined as process of generating new bone by stretching distraction osteogenesis, with traction on living tissue can stimulate and maintain regeneration and growth by inducing proliferation of precursor cells, the same cellular movement occurred with bone grafting ${ }^{[10,11]}$.

Oxidized regenerating cellulose (surgicel) been used by Skoog $1967^{[12]}$, he did research on bone formation by making an experiment on Rabbits by making sub periosteal pocket created over the frontal-nasal bone and loosely packed with surgicel soaked in blood. On histological examination, the tissue reaction was characterized by massive proliferation of fibroblasts and osteoblast and fine blood vessels formation.

This research quiet interesting, it does demonstrate the cytological changes associated with free bone grafting by formation of granulation tissue around the segments of bone with aggregation of platelets and released of growth factor (PDGF) with creeping mechanism of capillaries in the fallowing day derived from surrounding tissue, periosteum and bone marrow of bony segments of the mandible. The mesenchymal stem cells with fibroblasts and Platelets Derived Growth Factor (PDGF) played an important role in bone grafting. Rigid fixation required for promotion of good healing otherwise failure of graft could happen.

The object of this research is to demonstrate the histological acceptance of resected bony segments to free bone graft from iliac crest for restoration vitality, growth and function and the role of mesenchymal stem cells and growth factor in acceptance of bone graft and the role of Surgicel in healing process.

\section{Material and Methods}

\section{This divided into:}

\section{Animal model for the experiment}

1. Choice of animal model, there are certain requirements for choosing animal model ${ }^{[13]}$, the animal should carry a close comparative tissue resemble human tissue reaction for comparative studies, we might face difficulties during the technique been used in the experiment and its effect on masticatory process of the animal and also radiographic records of the experiment required to show radiographic changes with histological studies after the experiment ${ }^{[9]}$.

2. The animal should not carry any disease that could transmit to human and should be vaccinated before commencing the experiment. The cage of the animal required hygienic status, the researcher should be sterile and wearing surgical gown, mask, clove with special sterile shoes during working in animal lab and any other steps taken for safety measures of the researcher and animal.

3. The animal model chosen for this experiment was Rabbit very good animal model, because it is vegetarian, healthy looking, safe, not aggressive and friendly and does not carry disease to the researcher; also we can keep few Rabbits in one cage. Rabbit chosen because it is available, the cost is cheap and the animal clean and nice looking.

\section{Experimental study}

In this experiment we used twelve young male Rabbits of 3 months of age, weighted $1.25 \mathrm{~kg}$, divided in two groups of 5 and two Rabbits used as control, they were subjected to surgical osteoctomy by excising bone $1.5 \mathrm{~cm}$ from body of mandible and bone graft of $2 \mathrm{~cm}$ harvested from iliac crest after decortication of bony segments. The graft was fixed by soft stainless steel wire of $0.25 \mathrm{~mm}$ oxidized regenerated cellulose (Surgicel, Ethicon Sarl, Switzerland, Johnson \& Johnson Medical limited) was used to cover the graft of group B, sub mandibular incision was used for access to the mandible, after three months experiment was terminated. After operation the animals were sent to their cage and once recovered from anesthesia, animals started normal food chewing. [Figure 1a, 1b, 1c]

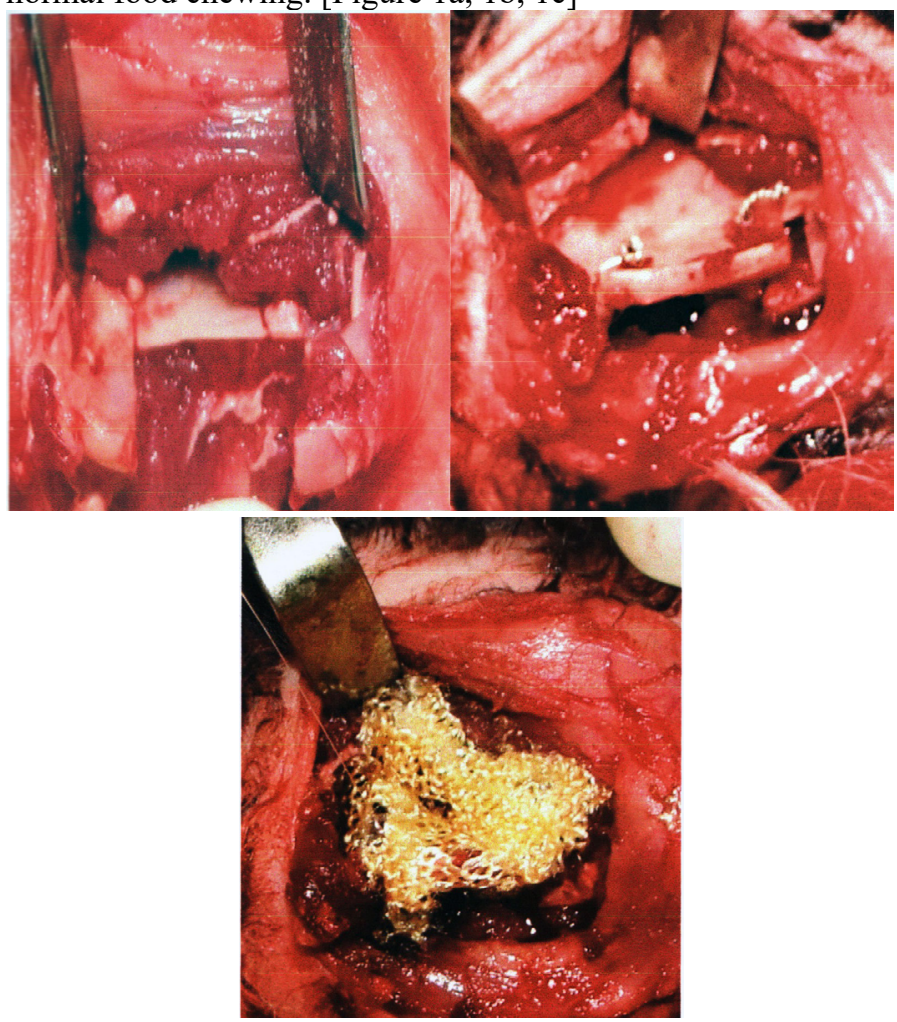

Figure 1: A: Photograph showing experimental resection of $1.5 \mathrm{~cm}$ of lower jaw of Rabbit and the two segments of the lower jaw, B: Photograph showing reconstruction of the defect by iliac bone graft of $2 \mathrm{~cm}$ and fixed firmly by soft stainless steel wire of $0.25 \mathrm{~mm}, \mathbf{C}$ : photograph showing Surgicel mesh cover iliac crest graft before soaking it by blood 
Citation: Kummoona, R., et al. Reconstruction of Lower Jaw by Iliac Bone Graft, Experimental Study on Rabbit and Role of Mesenchymal Stem Cells (2018) J Stem Cell Regen Biol 4(1): 20- 24.

\section{Anesthetics procedure}

The anesthesia started by induction the animal by Diazepam (1-2 mg / kg of body weight), anesthetic procedure carried out under ketamine IM of $30 \mathrm{mg} / \mathrm{kg}$ and Xylazine IM of $6 \mathrm{mg} / \mathrm{kg}$ of body weight with xylocaine $2 \%$ and adrenaline of $1 / 80000$ subcutaneously.

Immediate post operatively antibiotic of ceftriaxone of $20 \mathrm{mg} / \mathrm{kg}$ of body weight IM given and prescribed for 5 days

From ethical point of view, we have to provide the animal decent accommodation in a cage and we should present the food he likes with daily cleaning the cage to prevent the animal from any source of infection during period of experiment.

\section{Results}

The result were 2 Rabbits passed, one Rabbit end with infection and one with slight injury to sciatic nerve due to traction without effect on mastication. The dyed Rabbits and one with infection excluded from this experiment. At the end of experiment all animals neither showed restriction of mouth opening nor difficulties during masticatory process or deformity of the lower jaw. By the end of experiment all animals gain weight ranging from 0.1 to $0.3 \mathrm{~kg}$.

In the end of the experiment, the lives of the animals were terminated for postmortem and histological studies.

\section{Postmortem examination}

After removal of stainless steel wire, the mandible showed excellent healing of the graft, the mandible dissected for radiological assessment after 8 weeks, the graft without surgicel showed Slight delay of healing than graft covered by sugicel in group B. Specimens were immersed in $10 \%$ buffer formalin with $4-\mathrm{N}$ formic acid for decalcification for 10 days [Figure 2]

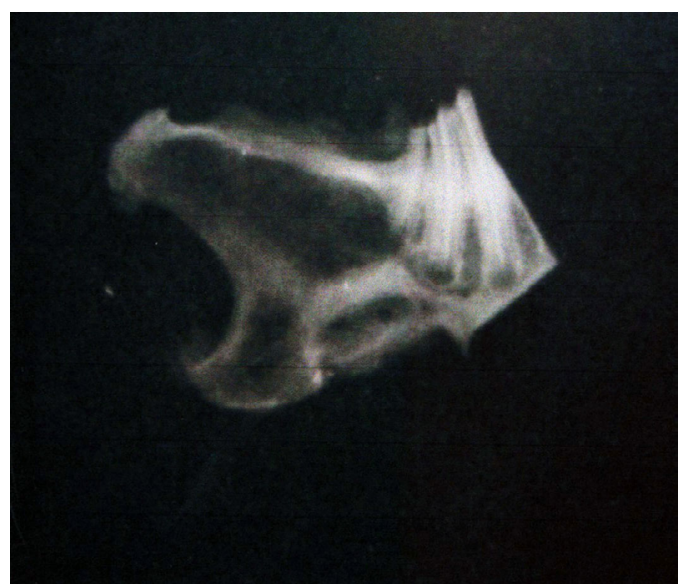

Figure 2: X-ray of specimen of Rabbit lower jaw showing bone grafting obvious in the lower border

\section{Histological examination}

The histological examination of dissected jaws was done to study the cellular changes during the first 2 weeks 4 weeks and 8 weeks and at the end of the experiment.

By Hematoxylin and Eosin staining (H\&E) we did observed a good amount of granulation tissues formed with mesenchymal stem cells and active fibroblast around the edges and fine blood vessels invading the graft with osteoblast in different shape, also few chondrocyte inside lacunae observed. in other area osteoblast showed more active and old bone showing medullary sinuses, it was more clear with cases with surgicel soaked with blood covering bone graft in group B. [Figure 3,A,B,C],

[Table1]

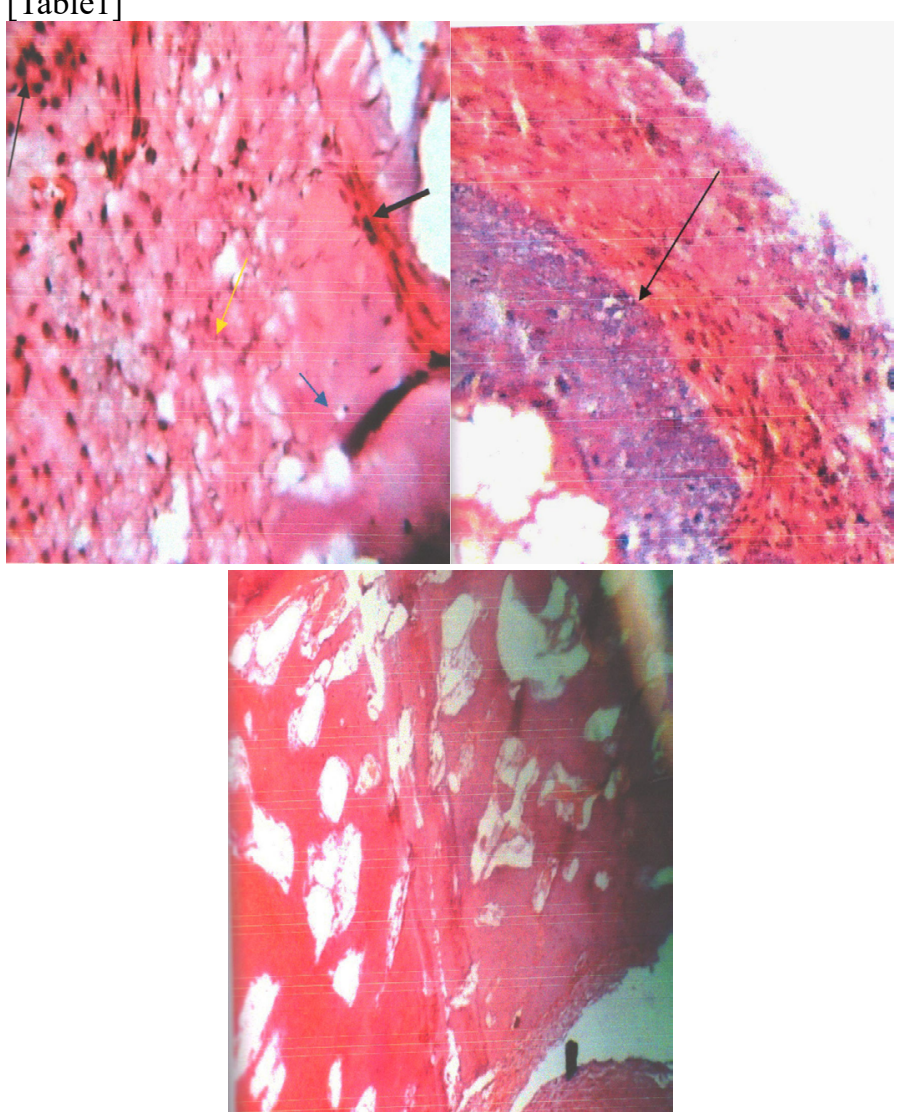

Figure 3: A: Histology of the graft showing mesenchymal stem cells invading the graft(H\&E 40X), B: Histology of bone graft showing healthy granulation tissue with mesenchymal stem cells with active fibroblasts (H\&E 40X), C: Histology of mature osteoid tissue formed from graft (H\&E 20X)

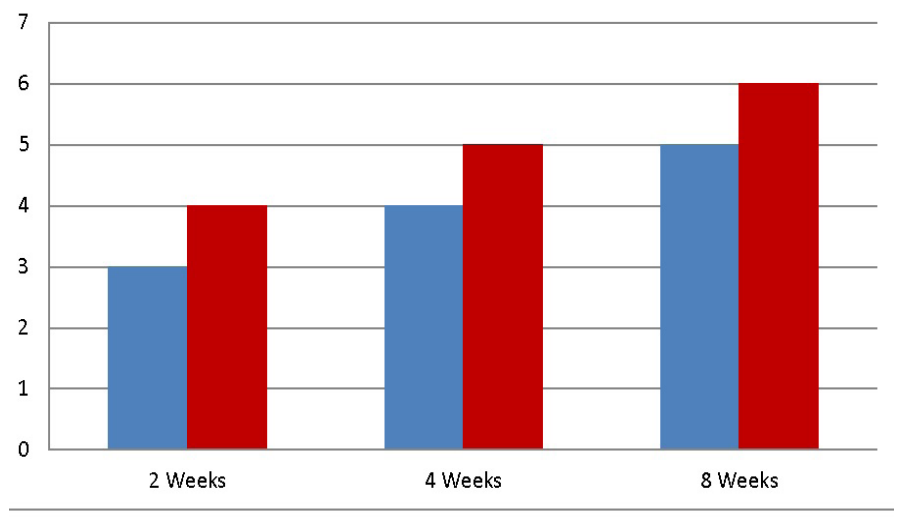

Group A

Group B

Table 1: showing the differences between healing process of group $A$ without surgicel application on bone graft and group B with application of surgicel

\section{Discussion}

Bone graft is widely practiced by maxillofacial surgeons, craniofacial surgeon and by orthopedic ${ }^{[3,5]}$, surgeons for reconstruction of defect by trauma or in cases withpost-traumatic missile war 
injuries and after radical tumor surgery. Bone graft also used for fusion of spine by orthopedic surgeons ${ }^{[5]}$.

In this research we used 12 male Rabbit divided into 2 groups 5 of each, group A and group B. Two animals used as control. In group B we did cover the graft by mesh of oxidized regenerating cellulose soaked in blood (Surgicel), the aim was to promote healing and bone induction. It was found by formation of clot and aggregation of platelets, the growth factor released (PDGF) and granulation tissue formed with release of mesenchymal stem cells and active fibroblast from bone marrow of two bony stumps and also from periosteum and covering muscles to accelerate the healing process and bone formation.

Our choice always was bone graft from iliac crest because of its curvature, shape and we can reshape the graft to simulate a mandible contour, and due to its rigidity as a cortical-cancellous bone graft characterized by its high vascularity. The donor defect of iliac crest was filled by surgicel as a good hemostasis and to induce bone formation in the gap created by harvesting bone graft. Once reconstruction done properly, healing process started with rigid fixation for 6 weeks fallowed by active mobilization of the jaw with bone graft to promote growth potential of the graft. This idea is based on theory of Moss $1968^{[6,14]}$, he did stated, growth of the face depend on functional demand of periosteal matrix of the facial skeleton, in children our choice for reconstruction of lower jaw is by rib graft ${ }^{[15]}$.

The process of acceptance of bone graft for reconstruction of boney defect is quiet complicated and the biological changes that occur with bone grafting is quiet interesting ${ }^{[1,3-5]}$. Immediately after24 hours capillaries started to invade the graft by creeping mechanism from surrounding tissues, the clot with healthy granulation tissue formation begin to form mesenchymal stem cells derived from bone marrow of bony stumps, the periosteum, muscle covering and cancellous tissue of the two segments on both sides of the mandible by influence of PDGF. The new bone formed invading the matrix of the graft. There is no latent period phase in grafting as in distraction technique ${ }^{[9]}$ but the maximum contact between the graft and two side bone ends of the mandible with rigid fixation of the graft to bony host with Inter Maxillary Fixation (IMF) in human, play an important role in healing of the graft beside high skill and experience in bone grafting. The presence of oxidized regenerating cellulous (surgicel) play an important role for acceleration of clot formation by aggregation of plat lets and release of PDGF growth factor with formation of granulation tissue and mesenchymal stem cells and active fibroblasts for osteoid tissue formation ${ }^{[12]}$.

The author advocating in 1986 Kummoona Chondro-Ossous graft $^{[2,7-9,13-19]}$ for reconstruction of the Temporomandibular Joint (TMJ) in children for correction of deformity, growth of the mandible and midface and also to restore growth, remodeling and repair of the condyle.

The growth potential of Kummoona Chondro-Ossous graft $^{[18]}$, is due to endogenous growth potential of the graft and due to presence of mesenchymal stem cells in granular cell layer with hypertrophic chondrocyte passed through series of changes for chondrocyte and osteoblast formation and bone marrow representing growth activity of the graft, it was also found that G-protein coupled receptor (CXCR4) predominantly expressed in hyper trophic chondrocyte, while its ligand chemokine stromal cells derived factor (SDF-1) is expressed in the bone mar- row adjacent to hypertrophic chondrocyte ${ }^{[13,17]}$.

We noticed from our research on Distraction technique ${ }^{[9]}$ previously and this research, the cellular changes that occur by distraction facilitated by tension stretch theory of illizarov $^{[10]}$ during latent phase, while our cellular changes in bone grafting technique was based on maximum contact between decorticated bone segments of the mandible and cortical-cancellous bone graft with firm and rigid fixation of the graft to bony segments of the mandible ${ }^{[6]}$ and covered by periosteum and muscle without tension or scar tissue. The healing process more accelerated in bone grafting by presence of oxidized regenerating cellulose (surgicel) ${ }^{[12]}$.

\section{Conclusion}

This research proved that mesenchymal stem cells and growth factor derived from platelets (PDGF) play an important role in bone grafting of the mandible and oxidized regenerating cellulose (Sugicel) was accelerating the healing process of bone graft.

\section{References}

1. Bone Grafting. John Hopkins Medicine health Library. Pubmed | Crossref | Others

2. Kummoona, R. Biological reconstruction of the temporomandibular joint by chndro-ossous graft, clinical and experimental study. (2013) J Craniofacial Surg 24(3): 792-796. Pubmed | Crossref $\mid$ Others

3. konttinen, Y.T., Warise, E., Xu, J.W., et al. Bone grafting. (1998) Current orthopedic 12(3): 209-215.

Pubmed | Crossref $\mid$ Others

4. Bauer, T.W., Muschler, G.F. Bone graft materials an overview of basic science. (2000) Clin Orthop Relat Res 371: $10-27$.

Pubmed | Crossref $\mid$ Others

5. Bone graft for spinal fusion. Pubmed | Crossref $\mid$ Others

6. Kummoona, R. Reconstruction of mandible by bone graft and metal prosthesis. (2009) J Craniofac Surgery 20(4): 1100-1107.

Pubmed | Crossref | Others

7. Kummoona, R. Pediatrics Maxillofacial injuries with special attention to fracture condyle. (2017) EC Pediatrics 5.6: 170-171.

Pubmed $\mid$ Crossref $\mid$ Others

8. Kummoona, R. Pediatrics and Children Facial deformity with special references to ankyloses of the Temporomandibular joint. (2018) EC Pediatrics 7.3: 112-115.

Pubmed | Crossref $\mid$ Others

9. Kummoona, R., Abdul, majeedjassim. Distraction technique of lower jaw on Rabbit Experimental Studies Research. (2017) J stem cell regenerative biolology 3(2): 158-162.

Pubmed | Crossref $\mid$ Others

10. Illizarov, G.A. The principle of Illizarov method. (1988) 
Bull Hosp Jt Dis Orthop Inst 48(1): 1-11.

Pubmed $\mid$ Crossref $\mid$ Others

11. McCarthy, JG., Staffenberg, D.A., Wood, R.J., et al. Introduction of an intraoral bone lengthening device. (1995) Plastic Reconstructive Surg 96(4): 978-981.

Pubmed |Crossref | Others

12. Skoog, T. Regeneration of facial periosteum and bone. (1974) Plastic Surgery book:ed Tord Skoog, Almqvist \& Wiksell international, 158-173.

Pubmed |Crossref | Others

13. Rhode island hospital report, recent advances in connective tissue cell development biology 2011.

Pubmed |Crossref | Others

14. Moss, M.L. The primary of functional matrices in orofacial growth. (1968) Dent Proct Dent Rec 19(2): 65-73.

Pubmed | Crossref | Others

15. Kummoona, R. Surgical Procedures Carried on Lower Jaw. (2017) Research Journal of Ear Nose and Throat 1(1:8).

Pubmed $\mid$ Crossref $\mid$ Others

16. Kummoona, R. Chondro-ossous iliac crest graft for one stage reconstruction of ankylosed TMJ in children. (1986) J Maxillofacial Surg 14(4): 215-220.

Pubmed |Crossref | Others

17. Kummoona, R. Role of mesenchyme stem cell of chondro-ossous graft for reconstruction of the temporomandibular joint for continuous growth of the mandible and midface. (2013) Annals of Oral Maxillofacial Surgery 1(1): 2.

Pubmed $\mid$ Crossref $\mid$ Others

18. Kummoona, R. Kummoona Chondro-Ossous graft good substitute to condylar growth center and fore correction of facial deformity in children. (2017) Arch Otolaryngol Rhinol 3(3): 098-102.

Pubmed |Crossref | Others

19. Kummoona, R. Kummoona Chondro-Ossous graft for reconstruction of the Temporomandibular Joint in Children. (2017) Arch Clin Exp Ortho 1: 001-03.

Pubmed | Crossref | Others
Submit your manuscript to Ommega Publishers and we will help you at every step:

- We accept pre-submission inquiries

- Our selector tool helps you to find the most relevant journal

- We provide round the clock customer support

- Convenient online submission

- Thorough peer review

- Inclusion in all major indexing services

- Maximum visibility for your research

Submit your manuscript at

https://www.ommegaonline.org/submit-manuscript 